\title{
Erişkinlerde İnvajinasyonların Çok Kesitli Bilgisayarlı Tomografi İle Değerlendirilmesi
}

\section{Evaluation of Invaginations by Multiple-Slice Computed Tomography in Adults}

\author{
Muhammed Akif DENiZ ${ }^{1}$ (D) Zelal TAŞ DENiZ ${ }^{2}$
}

1 Dicle üniversitesi Tıp Fakültesi, Radyoloji Anabilim Dalı, Diyarbakır

2 Sağlık Bilimleri Üniversitesi Gazi Yaşargil Eğitim Araştırma Hastanesi Radyoloji Kliniği, Diyarbakır

Öz.

Amaç: Bu çalışmanın amacı erişkinlerde karın ağrısı sebeplerinden biri olan invajinasyon olgularının bilgisayarlı tomografi (BT) görüntüleme özelliklerini ve etyolojik nedenlerini sunmak ve böylece invajinasyonun tanınabilirliğini vurgulamaktır.

Materyal ve Metod: Çalışmamızda Ocak 2010-Temmuz 2019 tarihleri arasında kliniğimize karın ağrısı nedeniyle başvurmuş ve intravenöz kontrastlı batın BT'de invajinasyon tanısı almış hastaların görüntüleri retrospektif olarak incelenmiştir. Hastalar; yaş ve cinsiyet, invajinasyon düzeyi, invaje segment uzunluğu, invajinasyon sebepleri açısından değerlendirildi.

Bulgular: Çalışmamızda 23 (\%52) ü erkek, 21 (\%48) i kadın olmak üzere toplam 44 hastanın kontrastlı batın BT si incelendi. Hastaların yaş ortalaması 39,1 (18-78) yıl idi. İnvajinasyon $8(\% 18)$ hastada kolon; $35(\% 79)$ hastada ince bağırsak, 1 hastada (\%2) ileokolik yerleşimliydi. Kolon invajinasyonlarında en sık neden $(\% 62,5)$ malignite, ince bağırsak invajinasyonlarında en sık neden $(\% 48,5)$ benign bir patoloji idi. Çalışmamızdaki bütün hastalar değerlendirildiğinde 10 hastada (\%23) malign bir patoloji, 20 hastada (\%45) benign bir patoloji izlenmiş olup 14 hastada (\%32) etyolojik faktör bulunamamış ve idiyopatik olarak kabul edilmiştir.

Invaje segment uzunluğuna bakıldığında kolon anslarında ortalama $5(2-20 \mathrm{~cm}) \mathrm{cm}$; ince bağırsak segmentlerinde ortalama 3,6 cm $(1-13 \mathrm{~cm})$ idi. Kolon anslarında nispeten daha uzun segment etkilenmişti.

Sonuç: Çalışmamızda invajinasyonların \%18 i kolon, \%79 u ince bağırsak yerleşimliydi. Toplam \%68 olguda etyolojide malign veya benign bir patoloji mevcuttu. Bilgisayarlı tomografi erișkinlerde karın ağrısının bir sebebi olan invajinasyonların tanısını kolaylaştırmakta ve etyolojik nedeni büyük oranda saptayabilmektedir.

Anahtar Kelimeler: Erişkin, İnvajinasyon, Bilgisayarlı Tomografi, Malignite

Abstract

Background: The aim of this study is to present the computed tomography (CT) imaging features and etiologic causes of invagination, which is one of the causes of abdominal pain in adults, and to emphasize the recognition of invagination.

Materials and Methods: In our study, images of patients who were admitted to our clinic for abdominal pain between January 2010 and July 2019 and diagnosed with invagination in intravenous contrast-enhanced abdominal CT were retrospectively analyzed. We evaluated the age and sex, level of invagination, length of invaded segment, causes of invagination.

Results: In our study, contrast-enhanced abdominal CT of 44 patients (23 (52\%) male and 21 (48\%) female) were examined. The mean age of the patients was 39.1 (18-78). Eight (18\%) patients had colon invagination, 35 patients (79\%) had small bowel and 1 patient (2\%) had ileocolic invagination.

Malignancy was the most common cause of colon invagination (62.5\%) and benign pathology was the most common cause of intestinal invagination (48.5\%). When all patients in our study were evaluated, a malignant pathology was observed in 10 patients (23\%) and a benign pathology was observed in 20 patients (45\%).No etiologic factor was found in 14 patients (32\%) and they were accepted as idiopathic.

When the length of the invaded segment was evaluated, it was found to be $5 \mathrm{~cm}(2-20 \mathrm{~cm})$ in colon invagination, $3,6 \mathrm{~cm}(1-13 \mathrm{~cm})$ in the small bowel segments. The relatively long segment was affected in the colon loops. Conclusion: In our study, $18 \%$ of invaginations were located in colon and $79 \%$ of small intestine. Sixty eight percent of total cases had malignant or benign pathology. Computed tomography shortens the diagnosis of invaginations, a cause of abdominal pain in adults, and can determine the etiologic cause to a large extent.

Key words: Adult, Invagination, Computed Tomography, Malignancy

\section{Sorumlu Yazar I \\ Corresponding Author}

Muhammed Akif DENIZ

Dicle Üniversitesi Tıp Fakültesi

Radyoloji Anabilim Dalı,

21280 Diyarbakır

Tel: +90 412 2588001-4314

Fax: 04122488216

e-mail: makifdeniz@yahoo.com

Geliş tarihi / Received:

05.03.2020

Kabul tarihi / Accepted:

05.08.2020

DOI: 10.35440/hutfd.698964 


\section{Giriş}

Barsağın proksimal segmentinin distal segment lümenine doğru teleskopik şekilde geçmesi veya bağırsak segmentlerinin iç içe geçmesi olarak tanımlanan invajinasyon (intussuseptum) tipik olarak çocuklarda görülmekle birlikte $\% 5$ civarında erişkinlerde de görülür (1-2).

Çocuklarda büyük oranda herhangi bir sebep bulunmazken, çocukların aksine erişkinlerde büyük oranda (\%70-90) benign (polip, leiomyom, lipom, granulom.vb) veya malign (primer tümör, metastaz, lenfoma.vb) sebeplere bağlı görülür(3). Ayrıca erişkinlerde kolon anslarındaki invajinasyonlarda neden olarak sıklıkla malignite, ince bağırsak düzeyinde invajinasyonlarda neden olarak sıklıkla benign durumlar söz konusudur(1).

İnvajinasyonlar etkilenen segmentlere göre; bağırsak invajinasyonu (jejunojejunal, jejunoileal, ileoileal), ileokolik invajinasyon ve kolokolik inavajinasyon şeklinde sınıflandırılırlar. Invajinasyon tanısı ultrasonografide (US) 'hedef' veya 'öküzgözü bulgusu' şeklinde tariflenen iç içe geçmiş bağırsak segmentlerinin görülmesi ile konabilir. Renkli doppler US'de invajinasyon içerisine giren ve bu segmentte dönen vasküler yapılar seçilebilir. Bilgisayarı tomografi (BT) de; erken evrede 'hedef bulgusu' şeklinde iç içe geçmiş bağırsak anslarının görülmesi ile tanı konur. Geç dönemde mezenterik yağın ve bağırsak duvar tabakalarının oluşturduğu tabaka şeklinde kitle lezyonu, vasküler yetmezliğe bağlı ödem veya mural kalınlaşma görülebilir(1). Bilgisayarlı tomografi invajinasyon tanısında en sensitiv modalite olup aynı zamanda invajinasyona sebep olmuş patolojinin ve invajinasyon sonucu oluşan patolojilerin görüntülenmesinde de oldukça başarııdır(4).

Erişkinlerde invajinasyonda karın ağrısı en sık semptomdur. Akut bağırsak tıkanıkığı sık değildir ve invajinasyon erişkinlerde bağırsak tıkanıklıklarının \% 1-3 ünden sorumlu tutulmaktadır. Hastaların çoğu subakut, kronik veya aralıklı semptomlar ile başvurur (5). Birçok araştırmacı, intestinal iskemi riski ve invaginasyonun etyolojisindeki olası malignite nedeniyle erişkinlerde invajinasyon vakalarını cerrahi endikasyon olarak görür (6-7). Bu nedenle erişkinlerde invajinasyonun tanınması ve sebebinin bilinmesi son derece önemlidir.

Amacımız erişkinlerde karın ağrısı sebeplerinden biri olan invajinasyon olgularının BT görüntüleme özelliklerini ve etyolojik nedenlerini sunmak ve böylece invajinasyonun tanınabilirliğini vurgulamaktır.

\section{Materyal ve Metod}

Çalışmamızda Ocak 2010-Temmuz 2019 tarihleri arasında Radyoloji Anabilim Dalımıza karın ağrııı nedeniyle başvurmuş ve Kontrastlı batın BT de invajinasyon tanısı almış hastaların görüntüleri retrospektif olarak incelenmiştir. Hastalar; yaş, cinsiyet, invajinasyon düzeyi, intussuseptum uzunluğu ve invajinasyon sebepleri açısından değerlendirilmiştir.
Hastaların radyolojik incelemeleri 16 dedektörlü BT (Toshiba Activion, Toshiba Medikal System Corporation, 1385, Shimoıshıgamı, Ottowara-SHI, Tochıgı 324-8550, JAPAN) ve 64 dedektörlü BT (Brilliance BT cihazı, Philips Medical Systems, Cleveland, Ohio, USA) cihazları ile non iyonik intravenöz kontrast madde verilerek yapıldı. Çekim öncesi tüm hastalara ön kol veninden 18-20 G bir kateter aracılığı ile damar yolu açıldı. İnceleme sırasında bilinci yerinde olan hastalara nefes tutturuldu. İnceleme supin pozisyonda yapıldı. Artefakt oluşturmaması için her iki kola baş hizasında olacak şekilde pozisyon verildi. Alınan görüntüler, iş istasyonunda (Philips Extented Brilliance Workspace Philips Medical systems, Best The Netherlands) değerlendirildi. Görüntüler öncelikle aksiyal kesitlerde incelendi. Daha sonra 3 boyutlu reformat görüntüler oluşturularak sagittal ve koronal kesitlerden de faydalanıldı. İnvajinasyon tanı kriteri olarak iç içe geçmiş bağırsak segmenti görünümü baz alındı. Invajinasyon düzeyi, uzunluğu, lokalizasyonu ve invajinasyona sebep olmuş patolojiler değerlendirildi. Verilerin analizinde tanımlayıcı istatistik yöntemleri kullanıldı. Tüm analizler Statistical Package for Social Sciences (SPSS Inc, Chi, IL) version 20 programı ile gerçekleştirildi. Veriler ortalama \pm standart sapma ve yüzdeler şeklinde ifade edildi. Verilerin normal dağılıma uyup uymadığı kontrol edildi.

Çalışmanın gerçekleştirildiği üniversite hastanesinden yerel etik kurul onayı alınmıştır (Dicle Üniversitesi Tıp Fakültesi Girişimsel Olmayan Klinik Araştırmalar Etik Kurulu 20/10/2019 tarih 206 nolu karar) .

Artefaktlı çekimler, normal anatomik yapının bozulması nedeniyle daha önce bağırsak cerrahisi geçirmiş hastalar, 18 yaş altı hastalar, kontrastsız veya yeterli kontrast madde verilmemiş çekimler çalışma dışı bırakıımıştır. Ayrıca çalışmamız invajinasyon olgularının BT ile değerlendirilmesini amaçladığından, invajinasyon tanısı almış ancak sadece USG görüntüleri olan ve BT görüntüleri olmayan hastalarda çalışma dışı bırakıımıştır.

\section{Bulgular}

Çalışmamızda ince bağırsak ve kolon segmentlerinde invajinasyonu olan toplam 44 hastanın Kontrastlı batın BT si incelendi. Çalışmamızdaki hastaların 23 (\%52) ü erkek, 21 (\%48) i kadın olup hastaların yaş aralığı 18-78, yaş ortalaması 39,1 idi.

Hastalar invajinasyon düzeylerine göre incelendiğinde invajinasyon; 3 hastada çıkan, 2 hastada transvers, 2 hastada inen ve 1 hastada transvers kolondan inen kolona olmak üzere toplam 8 (\%18) hastada kolon; 19 hastada jejunal, 14 hastada ileal, 2 hastada jejunoileal olmak üzere 35 $(\% 79)$ hastada ince bağırsak yerleşimliydi. Bir hastada (\%2) da ileokolik yerleşimliydi (Şekil 1-5) .

Kolonda invajinasyonu bulunan hastaların yaş aralığı 1878 , yaş ortalaması 51,2 yı; ince bağırsakta invajinasyonu bulunan hastaların yaş aralığı 18-75, yaş ortalaması 36,5 
yıl olup kolon anslarında invajinasyon daha ileri yaşlardaki hastalarda izlendi.

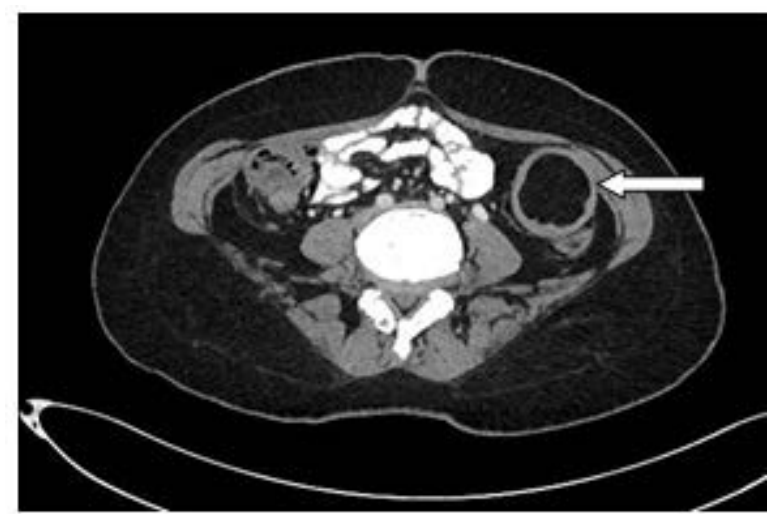

a

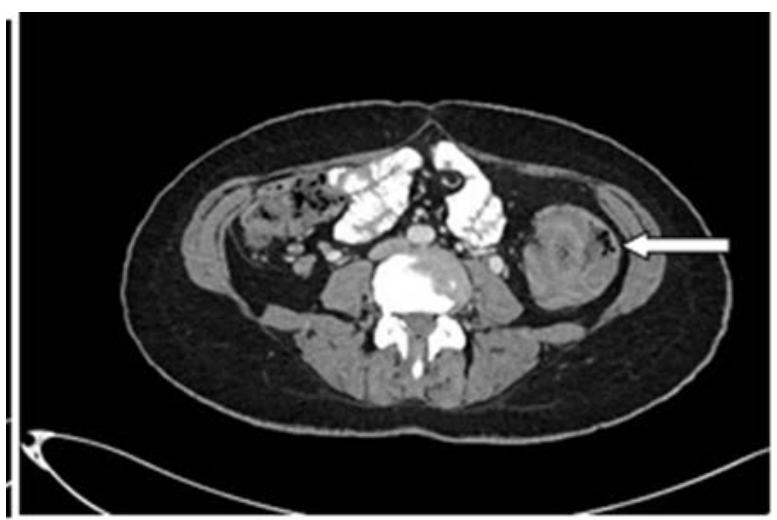

b

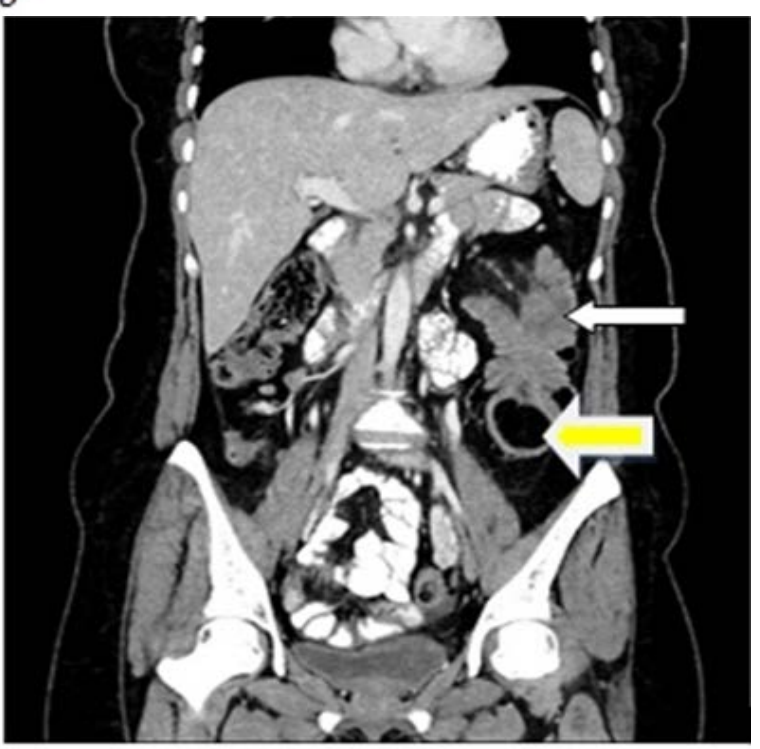

c

Şekil 1. 48 yaş kadın hasta, inen kolon düzeyinde lipom(a) ve axial (b) ve koronal (c) görüntüde inen kolonda invajinasyon

Invajinasyonlarda etyolojik nedene bakıldığında kolonda invajinasyonu bulunan hastalarda; 4 kolon kanseri, 1 metastaz (malign melanom) olmak üzere toplam $5(\% 62,5)$ hastada malignite, 1 hastada multipl polipler, 1 hastada lipom olmak üzere toplam 2 (\%25) hastada benign bir patoloji izlenmiş olup. $1(\% 12,5)$ hastada invajinasyon sebebi anlaşılamamış ve idiyopatik kabul edilmiş̧ir.

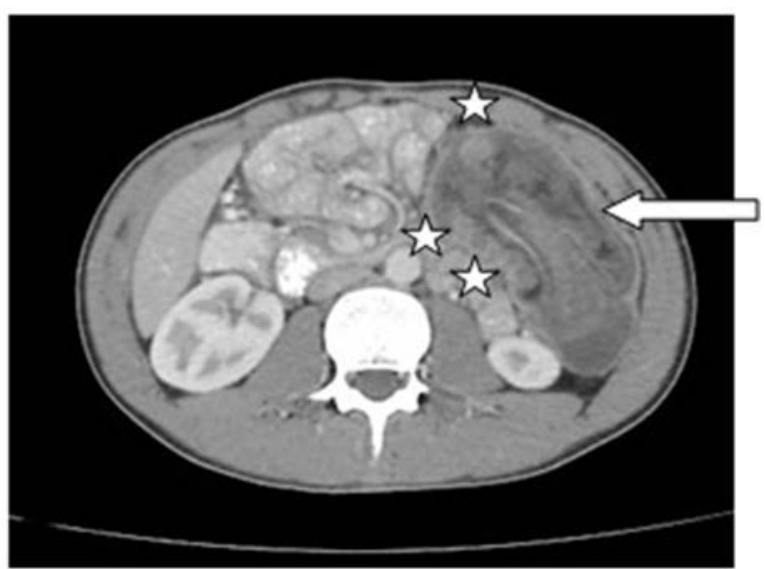

a

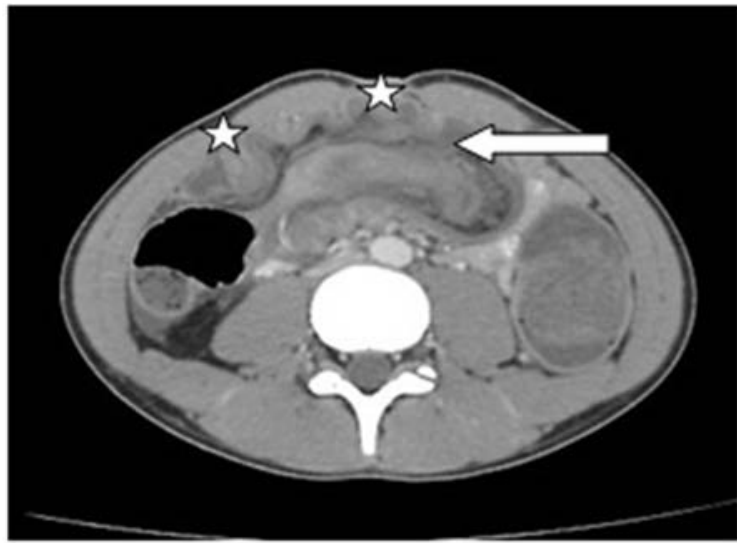

b

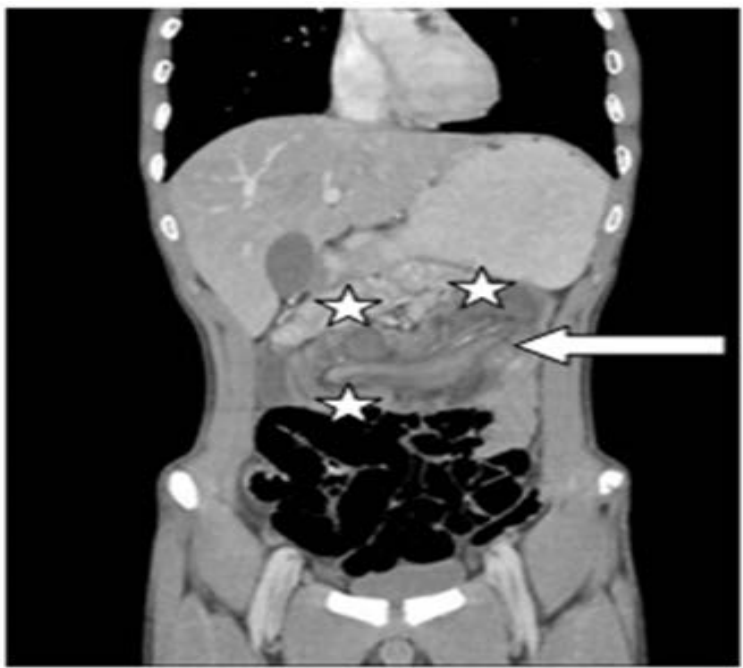

C

Şekil 2: 34 yaş erkek hasta, transvers kolon ve inen kolonda yaygın polip görünümleri (yıldız) ve kolon anslarında uzun segmenti etkileyen invajinasyon(ok) 


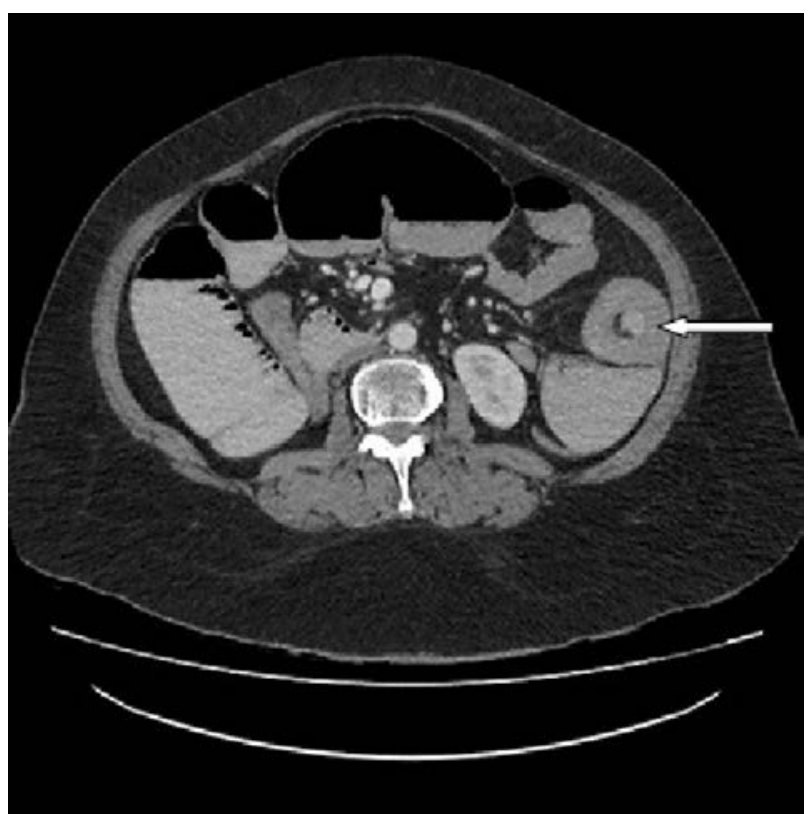

Şekil 3. 55 yaş kadın hasta, sol üst kadranda jejunal anslarda invajinasyon

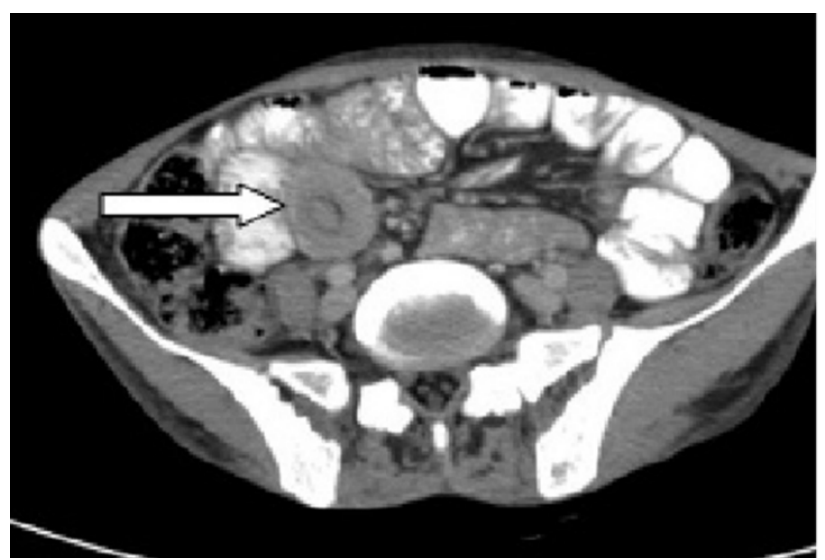

Şekil 4: 25 yaş kadın hasta, batın sağ alt kadranda ileal anslarda invajinasyon

Ince bağırsak invajinasyonlarında etyolojik nedene bakıldığında; 10 hastada büyümüş lenf nodları, 3 hastada polip, 2 hastada lipom ve 2 hastada postoperatif değişiklikler olmak üzere toplam $17(\% 48,5)$ hastada benign bir patoloji izlendi. Ayrıca ikisi jejunal, 3 ü ileal ans kaynaklı olmak üzere 5 (\%14) hastada malignite izlendi. On üç hasta (\%37) etyolojide herhangi bir neden bulunamadığından idiyopatik olarak kabul edildi. Illeokolik invajinasyon hastamızda etyolojik neden intralüminal yerleşimli lipom idi. ÇaIışmamızdaki bütün hastalar değerlendirildiğinde etyolojik faktörler arasında; 10 hastada (\%23) malign, 20 hastada (\%45) benign patoloji izlenmiş olup 14 hastada (\%32) etyolojik faktör bulunamamış ve idiyopatik olarak kabul edilmiştir.

İnvaje segment uzunluğuna bakıldığında kolon anslarında ortalama $5(2-20 \mathrm{~cm}) \mathrm{cm}$; ince bağırsak segmentlerinde ortalama 3,6 cm $(1-13 \mathrm{~cm})$ olup kolon anslarında nispeten daha uzun segment etkilenmişti. Çalışmamızdaki invajinasyonu olan bütün hastalar değerlendirildiğinde; tüm invajinasyon grubundaki invaje segment uzunlukları $1-20 \mathrm{~cm}$ arasında olup ortalama $4,07 \mathrm{~cm}$ idi.

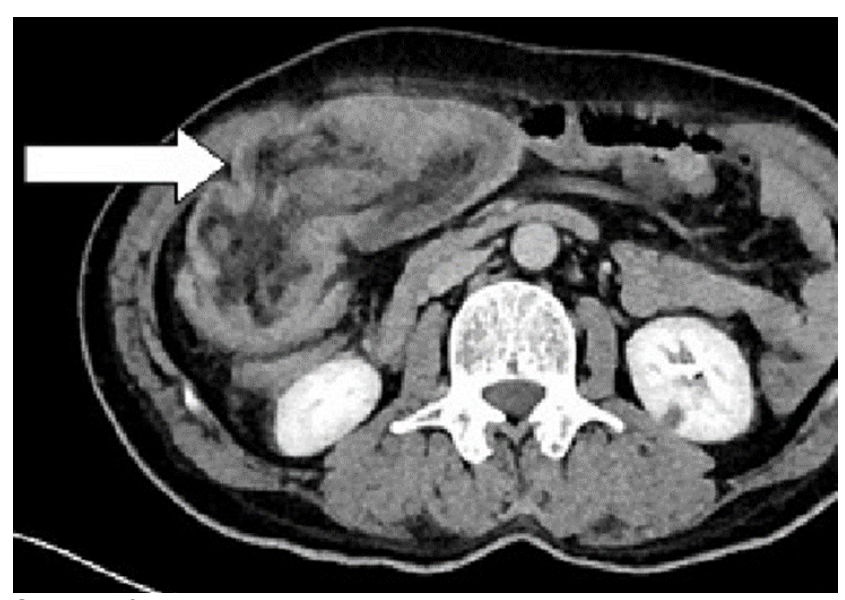

Şekil 5. 65 yaş erkek hasta, sağda transvers kolon düzeyinde kolon kanseri ile uyumlu asimetrik duvar kalınlaşması ve kolon anslarında uzun segmenti tutan invajinasyon

\section{Tartışma}

İnvajinasyon tipik olarak 2 yaş altı çocuklarda görülmekle birlikte invajinasyonların yaklaşık \%5 i erişkinlerde görülür (8). Yapılan çalışmalarda $(9,10)$ erişkinlerde saptanan invajinasyonlar genellikle 6-7. dekadlarda ve her iki cinsiyette benzer oranlarda görülmüştür. Bizim çalışmamızda literatür ile uyumlu olarak erkek-kadın oranları birbirine yakın olup hastaların \%52'si erkek, \%48'i kadındı. Hastalarımızın yaş ortalaması 39,1 yıl olup literatüre oranla daha erken yaşlar saptandı. Ancak kolonda invajinasyonu bulunan hastalar değerlendirildiğinde yaş ortalaması 51,2 yıl olup literatür ile uyumlu idi. İnce bağırsakta invajinasyonu bulunan hastaların yaş ortalaması 36,5 yıl olup kolon anslarında invajinasyon daha ileri yaşlardaki hastalarda izlendi.

İnvajinasyonların büyük bir bölümünün ince bağırsak kökenli olduğu bildirimistir (11-13). Yapılan çalışmalarda erişkinlerde invajinasyonların yaklaşık \%70-85'i ince bağırsak, \%15-30'u ise kolon kaynaklıdır (14). Bizim çalışmamızda literatür ile uyumlu olarak ince bağırsak invajinasyonları hastaların \%79'unda, kolon invajinasyonları hastaların \%18'inde saptanmıştı. Ayrıca yapılan bazı çalışmalarda ileokolik invajinasyon oranı \%15 olarak saptanmistir (15). Bizim çalışmamızda ileokolik invajinasyon oranı literatürde bildirilen oranlardan düşük olup sadece $1(\% 2)$ hastada saptanmıştır.

Erişkinlerde çocukların aksine invajinasyonların \%70-90' । organik bir patolojiye bağlıdır $(16,17)$. Bu nedenlerin yaklaşik \%65'ini benign ya da malign neoplazmlar, \%15-25'ini ise non-neoplastik nedenler oluşturmaktadır. İnce bağırsak anslarında invajinasyon çoğunlukla intra-extra lüminal bir patolojiye bağlı olup malignite $\% 30$ oranında görülür. 
Kolon anslarında invajinasyon \%60-70 oranında malign bir patolojiye bağıdır $(13,18,19)$. Çalışmamızda literatür ile uyumlu olarak ince bağırsak invajnasyonlarında malignite \%14 oranında bulunmuştur. İnce bağırsak invajinasyonu olan hastalarda $\% 48$ oranında benign patolojiler saptanmışken, idiyopatik nedenlerin oranı \%37 idi. Kolon invajinasyonları değerlendirildiğinde; literatür ile uyumlu olarak hastaların \%62,5'inde malignite ön plandaydı. Hastaların $\% 25$ 'inde benign patolojiler saptanmışken, kolon anslarında idiyopatik nedenlerin oranı \%12,5 idi. Çalışmamızdaki tüm hastalar değerlendirildiğinde hastaların \% 45' inde benign , \%23' ünde malign patoloji saptanmışken, idiyopatik oran $\% 32$ idi.

Çocukların aksine erişkinlerde invajinasyonların tedavisi, etyolojideki organik patolojiler ve invajinasyonun sebep olacağı intestinal iskemi riski nedeniyle, genellikle cerrahidir. Bilgisayarlı Tomografi cerrahi öncesi etkilenen bağırsak segmentlerini değerlendirmede son derece önemli bir modalitedir. Etkilenen bağırsak segment uzunluğunun bilinmesi cerrahi planlamada önemlidir (6-7). Çalışmamızda etkilenen segment uzunluğu kolon invajinasyonlarında ortalama $5 \mathrm{~cm}$, ince bağırsak invajinasyonlarında ortalama $3,6 \mathrm{~cm}$ ölçülmüş olup kolon invajinasyonlarında ince bağırsak invajinasyonlarına göre daha uzun segment etkilenmişti.

Hasta sayısının az olması, çalışmamıza sadece BT görüntüleri olan hastaların dahil edilmiş olması ve hastaların operasyon sonrası takiplerinin olmaması çalışmamızın kısıtıılı̆ını oluşturmaktadır.

Sonuç olarak çalışmamızda invajinasyonların \%18' i kolon, $\% 79$ ' u ince bağırsak yerleşimli olup etyolojide en sık neden olarak kolon invajinasyonlarının \%62,5' inde malign bir patoloji, ince bağırsak invajinasyonlarının \%48' inde benign bir patoloji saptanmıştır. Bilgisayarı tomografi erişkinlerde karın ağrısının bir sebebi olan invajinasyonların tanısını, seviyesini, etkilenen segment uzunluğunu ve etyolojik nedenini büyük oranda kolaylıkla saptayabilmektedir.

\footnotetext{
Açıklamalar

Etik Onam: Dicle Üniversitesi Tıp Fakültesi Girişimsel Olmayan Klinik Araştırmalar Etik Kurulu 20/10/2019 tarih 206 nolu karar.
} Çalışmamızda herhangi bir finansal kaynak kullanılmamış-
tır.
Çalışmamızda mevcut yazarlar dışında katkı sağlayan kişi/ kurum bulunmamaktadır.

\section{Kaynaklar}

1. Federle M. P, Jeffrey R. B, Woodward P. J. Diagnostic Imaging Abdomen İkinci baskı.2013;II-5.56-7.

2. Haas EM, Etter EL, Ellis S, Taylor TV. Adult intussusception. Am J Surg. 2003;186:75-6.

3. Gordon RS, O'Dell KB, Namon AJ, Becker LB. Intussusception in the adult-a rare disease. J Emerg Med. 1991;9: 337-42.
4. Azar T, Berger DL. Adult intussusception. AnnSurg 1997;226:134-8. 5. Chiang JM, Lin YS. Tumor spectrum of adult intussusception. J Surg Oncol. 2008;98(6):444-7.

6. Rea JD, Lockhart ME, Yarbrough DE, Leeth RR, Bledsoe SE, Clements $\mathrm{RH}$. Approach to management of intussusception in adults: a new paradigm in the computed tomography era. Am Surg. 2007;73(11): 1098-105.

7. Omori $\mathrm{H}$, Asahi $\mathrm{H}$, Inoue $\mathrm{Y}$, Irinoda $\mathrm{T}$, Takahashi M, Saito K. Intussusception in adults: a 21-year experience in the university-affiliated emergency center and indication for nonoperative reduction. Dig Surg. 2003;20(5):433-9.

8. Guillén-Paredes M.P, Campillo-Soto A, Martín-Lorenzo J.G, Torralba-Martinez J.A,Mengual-Ballester M, Cases-Baldó M. J et al. Adult intussusception-14 case reports and their outcomes. Rev Esp Enferm Dig. 2010;102(1):32-40.

9. Begos DG, Sander A, Modlin IM. The diagnosis and management of adult intussusception. Am J Surg. 1997;173: 88-94.

10. Weilbaecher D, Bolin JA, Hearn D, Ogden W. Intsussusseption in adults. Am J Surg.1971;121: 531-5.

11. Yakan S, Calıskan C, Makay Ö, Deneçli A.G, Korkut M.A. Intussusception in adults: Clinical characteristics, diagnosis and operative strategies. World J Gastroenterol. 2009;15(16): 1985-9.

12. Barussaud M, Regenet N, Briennon X, de Kerviler B, Pessaux $P$, Kohneh-Sharhi $\mathrm{N}$ et al.Clinical spectrum and surgical approach of adult intussusceptions: a multicentric study. Int J Colorectal Dis. 2006;21: 834-9.

13. Erkan N, Haciyanli M, Yildirim M, Sayhan H, Vardar E, Polat AF. Intussusception in adults: an unusual and challenging condition for surgeons. Int J Colorectal Dis. 2005; 20: 452-6.

14. Wang N, Cui XY, Liu Y, Long J, Xu YH, Guo RX et al. Adult intussusception: a retrospective review of 41 cases. World J Gastroenterol. 2009;15(26):3303-8.

15. Harlak A, Öztürk G, Altınel Ö, Mentes Ö, Özer T, Demirbas S ve ark. Erişkinlerde Görülen İntestinallinvajinasyonların Klinik Seyri. The Eurasian Journal of Medicine.2007;39:37-40.

16. Prater JM, Olshemski FC. Adult intussusception. Am Fam Physician. 1993; 47:447-52.

17. Aras A, Akarsu C, Çikot M, Kocataş A, Alış H. Erişkinlerde İntestinal Invajinasyon; Tanı ve Cerrahi Tedavi. Van Tıp Dergisi.2015;22(1):14-8. 18. Ishii M, Teramoto S, Yakabe M, Yamamato H, Yamaguchi Y, Hanaoka $Y$ et al. Small Intestinal intussusceptions caused by percutaneous endoscopic jejunostomy tube placement. J Am Geriatr Soc. 2007; 55: 2093-4.

19. Archimandritis AJ, Hatzopoulos N, Hatzinikolaou P, Sougioultzis S, Kourtesas D, Papastratis $G$ et al. Jejunogastric intussusception presented with hematemesis: a case presentation and review of the literature. BMC Gastroenterol. 2001;1:1. 